\title{
Identity Crisis of Teenagers with Hearing Impairment in Palestine
}

\author{
Suheir .S. Sabbah ${ }^{1}$ \\ ${ }^{1}$ ALQuds University, Palestine \\ Correspondence: Suheir.S. Sabbah, ALQuds University, Palestine. E-mail: saheerquds@yahoo.com
}

Received: June 27, 2013 Accepted: August 11, 2014 Online Published: August 20, 2014

doi:10.5539/ass.v10n17p229 URL: http://dx.doi.org/10.5539/ass.v10n17p229

\begin{abstract}
This study aimed at identifying the degree of identity crises of teenagers with hearing impairment and the levels of the dimensions of this crises and revealing the impact of the following variables: gender, grade, economic level, age, degree and nature of the difficulty on the degree of the identity crisis. The results showed the identity crisis of the teenagers with hearing impairment was. Ideological Ego Identity, Interpersonal Ego Identity, relation with the other sex, and Identity verses role confusion. There were statistically significant differences in the identity crisis of the teenagers with hearing impairment attributed to the variables: gender in favor the category (18-20 years) and the degree of disability in favor of the moderate disability. There were no differences in the identity crisis of the teenagers with hearing impairment attributed to the variables (gender, grade, economic situation and nature of the disability).
\end{abstract}

Keywords: identity crisis, teenagers, people with hearing impairment

\section{Introduction}

Adolescence is one of the most important stages in human life because it contains many basic changes in the mental, physical, social and emotional growth (Bauman, 2012). Others considered adolescence a new birth for the individual as Hall described it as: "it is the stage of psychological crises, suffering, depression, anxiety, problems". And this critical period of age could refer to the formation of ego identity according to Erikson's theory. The formation of the ego identity is linked with the ability of identifying the teenager's beliefs and his roles in life through making decisions towards critical topics and questions and this what Erikson named Ego identity crisis as: "Who am I?, What do I want?, What are my dreams?. And so the teenager is in the crossroad during this process till he could have specific answers help him achieving his identity. While the teenagers' failure and diffusion in identify is represented in the failure in accessing into answers for these questions and in identifying the teenager's aims and roles in life (Sultan, 2009). In the stage, the youth face many problems; some of them related to physical or psychological health, or his situation in the family or his environment and other problems related to his work circumstances or his free time. The teenage has different situations according to the differences in the habits, traditions and environmental values and according to the State's philosophy towards its citizens (Kafakuis, 1996). Willic pointed that the most important obstacle facing the teenager is developing the ego identity to be more stable and this identity ends when the adulthood starts (Al-Munizl, 1994). Also, Konopka stated that adolescence is considered the stage where the individual achieve the process of accomplishment or solve the identity's problem (Al-Munizl, 1994). And Erikson (1902-1994) is the one who introduced the concept of identity into psychology as his theory which is about social and psychological development considered an extension of the psychological analysis and it represented the American image of Fruid's theory after getting rid of the high concentration on the entrainment and instincts (Abdalgader, 1984).

The disabled face in the adolescence two embarrassed situation: the first one concerning his disability as he faces many problems in his school, society and psychology situation and the other is related to the adolescence itself; the teenager's awareness of the nature of the imposed constraints on him because of his disability is developed and therefore his understanding of the concept of himself will be affected negatively as a result of these constraints. So the disabled will lose his trust of his abilities although the adolescence is considered a difficult and critical stage for all the teenagers, but it seems to be more difficult at the deaf handicapped teenagers because this disability in itself forms a crisis (Bdallh, 2004).

The hearing disability could be a reason for the identity problem because it is linked with the deaf disabled teenagers' high level of job performance's shortage and therefore their independence and self-appreciation will 
be affected. To have his identity developed, the people with hearing disability should have his own philosophy based on his understanding himself. And when he succeeded in doing so, it means that he has been developed socially and psychologically and he is ready to move to adulthood stage. Some of the indicators of this success are as follows: independency, values' acquisition, accepting his gender, identifying his goals and purposes, acquiring many principles that guided his life (Fahmi, 1978, p. 14).

\subsection{Problem of the Study \& Its Questions}

The statistics of the Deaf in the Palestinian central bureau of statistics for the year 2011 pointed that the ratio of the hearing disability according to other types of disabilities equals $15.5 \%$ in the West Bank and based on this, the researcher found that this category with hearing impairment represented an important ratio in the society in general. Undoubtedly, the hearing disability affects the society but its effect on the individual with disability is greater. They lost one of the necessary and important whether in acquiring the knowledge or in interacting with the environment so based on this, the focus of this study was on the people with hearing impairment to understand the development of their identity's nature and therefore, the problem of the study is summarized by the following major question:

1. What is the degree of identity's crisis of the teenagers with hearing impairment?

2. Are there statistical significant differences at the level of significance $(a \geq 0.05)$ in the identity's crisis of

Teenagers with hearing impairment attributed to the gender, age, economic situation, degree and nature of difficulty's variables?

\subsection{Significance of the Study}

This study concentrates on the teenagers with hearing impairment and understanding the development of their identify for its influence in the treatment on one hand, and providing services, requirements plus needs to them in the other hand.

This study may help the centers of special needs, the educational and public libraries plus decision makers in the field of the school and university education to reduce the degree of the Identity Crises of Teenagers with Hearing Impairment.

Because the disabled issue is considered one of the problems facing the society and which could be an obstacle in front of the development plans in different countries, this issue has recently witnessed more local and international interest to achieve higher degree of the educational, social, psychological attention of the disabled so as to get benefit of their abilities in the plans of development and to empower them as well.

The impotence of the level of adolescence which is addressed in this study as it represented one of the most developed levels which is characterized by psychological and physiological that could affect the teenagers' identity's crisis.

\subsection{Objectives}

To identify the degree of the identity crisis of the teenagers with hearing impairment in Palestine.

To identify the differences in the identity's crisis of the teenagers with hearing impairment which are attributed to variables as gender, age, type and degree of difficulty and the economic situation.

\subsection{Limitations of the Study}

This study was applied on the teenagers with hearing impairment in the Deaf schools in West Bank in Palestine during the first semester for the scholastic year 2013-2014

\subsection{Terms of the Study}

\subsubsection{Identity}

Marica differentiates between the four statuses of identity formation: diffusion, foreclosure, moratorium, and achievement. (Kroger \& Marica, 2010).

It is an inner psychological state including the individual's feeling of individualism, unity, Sameness and Continuity represented by the individual's sense of correlation between his past, present and the future and finally, his sense of the social cohesion represented by the correlation of the social samples and feeling of social support which is resulted from this correlation (Ghamid, 2001, p. 3) 


\subsubsection{Identity Crisis}

The struggle which is imposed on the teenager while he was trying to achieve the sense of identity that is characterized by trust and security. And when he failed in doing so, he felt confused, isolated from others, and he has weak social relations

(Misn, 1986, p. 537). Procedurally, it is the degree which the teenager with hearing disability gets in the questionnaire of the identity crisis with its different dimensions.

\subsubsection{Adolescence}

Al-Dosoqi (2003, p. 145) defines adolescence as an developed stage in the developed stages located between childhood and adulthood and this stage represented a critical period; it needs a new kind of adaptation that differs from what the individual used to do before and it is usually started at the end of childhood and ended at the end of adulthood.

\subsubsection{Hearing Disability}

It is a public expression covers a wide range of hearing -loss degrees which range from deafness that hinder the process of learning speech and language to the simple loss which does not hinder the ear's function in understanding the speech. (Al-Qurait, 2005, p. 299).

\subsubsection{Hearing Impairment}

In the conferences of White house for the baby health and protecting him, some researchers defined people with hearing impairment as: they are the children whose speech skill and the ability to understand the language was formed and later their hearing disability was developed. Those children are aware of the sounds and they have simple and usual contact with the world of sounds (Abdrahim, 1997, p. 214). In contrast, the conference of the American schools' principles disagreed with this diagnosis and they asserted that the children with hearing impairment are the children who have a problem in hearing sense but it still does its duties using hearing instruments (Bellis, 2013, p. 25).

\subsubsection{Difficulty of Hearing Disability}

The Palestinian Central Bureau of Statistics defined the difficulty of hearing disability as: the people who have some difficulties in hearing which hinder their ability of performing any part or any side in the daily activities as the difficulty of hearing a person taking in a crowded place or the inability of hearing a person taking directly to him with a normal voice (without shouting, or loud voice) and identifying who could not hear with one ear or both.

\section{Previous Studies}

Identity crisis is considered one of the most crises facing the individual through his passing the eighth stages which Erikson suggested because it occurs in one of the most sensitive stages that is affected by many factors as personal and social ones. The cultural and ideological factors as also considered the most influential in forming the identity. Specialists believed that lack of controlling the developmental stages educationally, many crises would appear particularly the identity crisis and then there is a need to pay much attention to the people with disability (Abdalgade, 1984).

Abo Hatab (1990, p. 393) assured that feeling of identity indicate that the individual keep an image of himself represented continuity and symmetry which matched with the symmetry and continuity created by others about him. And this feeling of identity means the teenager's success in reaching to personal belief or the necessary personal commitments in different fields of life as the commitment in a specific work (professional commitments, following ideas or specific ideologies etc. (Soliman, 1988, p. 4).

And Al-Ghamidi (2001) thinks that the ego identity is formed according to the previous dimensions through identifying four ranks to the identity relying on the appearance or the absence of two standards; Ego Identity Crisis or Exploration in one hand and the commitment on the other hand.

The model of Erikson of the social and psychological growth represented the ego identity versus the role-confusion and growth crisis in the adolescence and solving it positively is a basic requirement for the continuation of the healthy growth and to achieve independency. And the process of formation started at a degree of anxiety and combined Moratorium with the appearance of crisis which is related to the teenager's identification of the meaning of his existence through looking for principles, goals and social roles. Identity formation started by raising the following questions: Who am I?, What is my role in life? And Where am I going? And the formation process became clearer when the teenagers chose what suited his abilities and tendencies 
from these beliefs, roles and goals. Solving the crisis positively or negatively depends on the nature of growth through the previous stages that he passed by. In other words, the nature of solving the previous growth crises positively or negatively in one side and the different social or physical situations surrounded him on the other side and later the nature of the psychological structure which is based on all of it.

In ideal situations, the crisis is solved at the end of adolescence stage and the individual is able to form a clear and integrated image of his identity and has the ability to solve the conflict plus reconciling urgent personal needs and the public needs (Abdalamoti, 1991).

But if the crisis was not solved, it is possible to imagine the following three types of factors that could cause the teenager's identity crisis: Factors related to the past formation of the individual's personality. Factors related to the present: values, standards and the common situations in his society and in the culture he lives in (Ismael, 2001, p. 165).

Ali's study (2007) recorded cases of the ideological and interpersonal ego identity and the differences between the ranks (achievement, Moratorium, Foreclosure and diffusion) and the relation between them and the level of Psychological alienation. The results revealed in terms of the interpersonal ego identity that there were differences according to the gender and specialization variables in the levels of achievement, Moratorium, Foreclosure and diffusion (Hmoud, 2009, p. 570).

The study of Khatab (2007) aimed to identify the relation between the methods of facing identity crisis and the psychological independence of the blind handicapped teenagers and to identify the most common ranks of identity among the blind handicapped teenagers aged from 18 to 21 . The study concluded there was a positive correlation between the identity achievement and the psychological independence of the blind handicapped teenagers and there was negative correlation between Identity Diffusion and the psychological independence of the blind handicapped teenagers. Achievement rank was the most common one among blind handicapped teenagers aged between 18-21.The results showed also lack of impact to the gender and degree of difficulty variables on the psychological independence of the blind handicapped teenagers (Al-Wahidi, 2012, p. 110).

Wafi's study (2006) aimed at identifying the relation of the Behavioral disturbances with the level of psychological compatibility and its four dimensions (personal, school, family, physical). The sample of study represented the deaf and blind children. The results revealed differences between the deaf children who are behaviorally disturbed and who are not. While there were no differences between the blind children who are behaviorally disturbed and who are not. Additionally, there were no differences in the level of the psychological compatibility at the children attributed to the type of the disability (deaf, blind).

And the study of Al-Ashgar (2002) aimed to identify the services provided to the deaf children and its relation to their personal traits in Ghaza District. The study concluded that lack of self confidence and shyness were the most significant traits of the deaf children, and there statistical significant differences in favour of the females and there were no differences in the traits of shyness and lack of trust of others for whom received rehabilitation services.

And the study of Aseeri (2004) revealed the nature of ego identity's formation and its relation with self concept and psychological, social and general compatibility of the female secondary students in Ta'ef city. The results revealed that there were no relation between the degrees of the social identify and the degrees of self concept and the compatibility in the level of achievement or between the degrees between lock and the degrees of self-concept.

The study of Tylor and others (2006) aimed at showing the formation of the ethnic identity during the adolescence in the identity crisis of the teenagers in Philippines, china, India and El Salvador. The results showed family education played a major role in the process of forming the social identity and belonging regardless the teenagers' ethnic background. The reports of the teenagers were connected positively with discovery and commitment of their identities. And these results were compatible with the experimental work which sees family education as the basic component in forming the children's identity and the theoretical perspective that assured the family's role in identity's formation according the cultural tools (Hmood, 2009, p. 752).

The study of Picciotto (1987) aimed at testing the relation between sex, the school level and the development of identity. And the most significant results were the statistical significant differences between the gender in achieving the identity in favor of females and there were differences in favor of the high school level (Al-Wahidi, 2012, p. 113) 
The study of Adams \& Jones (1983) identified the relation between patterns of social nurture and the identity. The results revealed negative statistical relation between the scales of the acquired statuses which enhances the discriminated validity of Objective Measure of Ego Identity Status (OM-EIS). The results also showed negative statistical significant relation between the scales of the limited status of identity and there was positive statistical significant relation between the scales of delayed status. The significance of variation of the age showed that the mid-adolescence was not critical stage to distinguish the age according to the females students of the secondary stage. The researcher concluded a statistical relation between the patterns of an acquired social nurture through parents and between the identity status (Al-Tashawi, 2002, p. 61).

After addressing the previous studies, the current study is distinguished from these previous studies is that it is the first one that is conducted in Palestine and it addressed a very important issue. additionally, it is applied on people with hearing impairment and tries to fill the gap of the shortage of the studies concerning this field in Palestine as it tried to cover the topic of identity crisis and effect of some variables as identify issue and its relation to teenagers, age, economic status, degree and nature of difficulty) to the contrary of the previous studies which addressed the identity issue and its relation to the teenagers without having studies showed the identity crisis in the teenagers with hearing impairment.

\section{Methodology \& Procedures}

\subsection{Methodology}

To achieve the objectives of the study, the analytical descriptive approach was used.

\subsection{Population of the Study}

The population of the study consisted of all the people with hearing impairment in the West Bank with 15.5\% according to the Palestinian Central Bureau of Statistics for the year 2011.

\subsection{Sample of the Study}

The researcher used a simple random sample of teenagers with hearing impairment in Palestine consisted of 36 male and 64 female from the seventh grade till the first secondary one aged from 12 to 19.

\subsection{Description of the Sample's Variables}

Table (1) illustrates the distribution the sample of the study according to the study's variables:

Table 1. Distribution of the sample of the study according to the study's variables

\begin{tabular}{cccc}
\hline Variable & Level & N & Proportion \\
\hline \multirow{2}{*}{ Gender } & Male & 36 & 36.0 \\
& Female & 64 & 64.0 \\
Age & 13-less than 15 & 30 & 30.0 \\
& 15 -less than 18 & 30 & 30.0 \\
Grade & $20-18$ & 40 & 40.0 \\
& $9-7$ & 38 & 38.0 \\
Economic status & $12-10$ & 62 & 62.0 \\
& Less than 1000 & 28 & 28.0 \\
\multirow{3}{*}{ Degree of difficulty } & $1000-2000$ & 28 & 28.0 \\
& More than 2000 & 44 & 44.0 \\
Nature of difficulty & Simple & 16 & 16.0 \\
& Moderate & 60 & 60.0 \\
& Strong & 24 & 24.0 \\
& Genetic & 74 & 74.0 \\
\hline
\end{tabular}

It is clear from the previous table that the number of the females in this study was $64 \%$ out of the total sample of the study while the males number was $36 \%$. The reason for this disparity is due to the available number at the place of meeting the sample. The same table also showed the economic status as a distinguished difference as $28 \%$ of the sample's income was less than 1000 shekel which showed the difficult financial situation of the sample of the study. 
Study's instrument (a questionnaire of the identity's crisis):

The researcher used a questionnaire of identity's crisis after it was prepared and designed in addition to the help of other measurements which are: Rasmussen's measurement, identity crisis to Ahmad Mohmmad Mahmoud and the objective measurement to Hussein Abdalfatah Al-Ghamdi. The items which were taken from these measurements were developed to suit the study and the measurement in its final copy consisted of 33 items and it includes the following dimensions as it is illustrated in table (2).

Table 2. A questionnaire of the identity's crisis by items

\begin{tabular}{ll}
\hline Dimensions & N of items \\
\hline Trust versus Mistrust of oneself and others & $8-7-6-5-4-3-2-1$ \\
Identity vs. Role Confusion & $15-14-13-12-11-10-9$ \\
Ideological ego identity & $16-21-20-19-18-28-27-26-25-24-23$ \\
Interpersonal social identity, entertainment, relation with the other gender & $17-33-32-31-30-29-22$ \\
\hline
\end{tabular}

\subsection{The Instrument's Validity}

The questionnaire was designed initially and it was checked by a group of arbitrators to assert its suitability for the its purpose and the correctness of forming the items, and on the other hand to check the instrument validity by calculating Pearsons Correlation Coefficient of the total degree of the instrument and it was clear that there was statistical significance in all the questionnaire's items which indicated internal validity between the items.

\subsection{Reliability}

To assure of the study's instrument, the researcher calculate the reliability of the total degree and the fields of the reliability coefficient using Cronbakh Alpha and the total degree was (0.796) indicating the reliability of the instrument which is considered appropriate for the study's purposes.

\subsection{Independent Variables}

Gender (male-female)

Age (13-less than 15), 15-less than 18), 18-less than 20).

Economic status: less than 1000 sheqels, 1000-2000 sheqels, more than 2000)

Degree of disability: simple, moderate, low)

Nature of disability (genetic, non-genetic)

Dependent variable: degree of the identity's crisis

\section{Results}

This part of the study includes the results and shows the impact of the variables through the sample's responses and the statistical analysis. And to determine the degree of the means of the respondents' answers, data in table (3) shows the following grades were adopted.

Table 3. Degree and the means of the respondents' answers

\begin{tabular}{cc}
\hline Degree & Mean \\
\hline Low & Less than 1.66 \\
Moderate & $2.33-1.67$ \\
High & more than 2.34 \\
\hline
\end{tabular}

Results concerning the first question: "What is the degree of the identity's crisis of the teenagers with hear impairment?". To answer this question, means and the standards deviations were calculated.

The previous table illustrated the means and the standard deviations of the respondents' answers regarding the identity's crisis of the teenagers with hear impairment. The mean of the total degree is 2.12 with a standard deviation (0.3701) indicating the degree of the identity's crisis of the teenagers with hear impairment is moderate. there were two items whose degrees were high while 29 items' degree was moderate and two items' degree was 
low. And the following items "I feel embarrassed when talking to others" and "I still need my family and their help to me", have the highest mean while "I do not like attending the social occasions" the lowest mean.

Table 4. Means \&Standard deviations of the respondents' answers

\begin{tabular}{|c|c|c|c|c|}
\hline $\mathrm{N}$ & Items & Mean & Std & Degree \\
\hline 21 & I still need my family and their help & 2.34 & 0.544 & High \\
\hline 22 & I feel embarrassed when talking to the other sex. & 2.54 & 0.679 & High \\
\hline 26 & I could not choose the suitable work & 2.22 & 0.679 & Moderate \\
\hline 27 & I find difficulty in studying the school subjects. & 2.22 & 0.616 & Moderate \\
\hline 18 & I feel happy. & 2.12 & 0.480 & Moderate \\
\hline 20 & I feel others' sympathy towards me. & 2.12 & 0.594 & Moderate \\
\hline 1 & There is no one who can understand me & 2.10 & 0.505 & Moderate \\
\hline 17 & I wish I could enjoy my life & 2.10 & 0.678 & Moderate \\
\hline 19 & I sometimes feel worry and anxiety & 2.08 & 0.444 & Moderate \\
\hline 33 & I do not have specific hobby or activity. & 2.02 & 0.795 & Moderate \\
\hline 25 & I do not have future plans or goals & 2.00 & 0.808 & Moderate \\
\hline 24 & I feel I could not make any decision concerning my & 1.98 & 0.714 & Moderate \\
\hline 3 & I do not trust others & 1.94 & 0.793 & Moderate \\
\hline 2 & People are no honest in dealing & 1.90 & 0.463 & Moderate \\
\hline 9 & I wish I was someone else. & 1.88 & 0.872 & Moderate \\
\hline 31 & My collogues describe me as a sad person. & 1.88 & 0.746 & Moderate \\
\hline 29 & I feel I am not welcomed among my colleagues. & 1.86 & 0.783 & Moderate \\
\hline 30 & I feel embarrassed when my colleagues criticize me. & 1.86 & 0.572 & Moderate \\
\hline 11 & I feel my disability and appearance hinder my progress. & 1.84 & 0.584 & Moderate \\
\hline 23 & I feel I won't succeed in my practical life. & 1.84 & 0.650 & Moderate \\
\hline 13 & I cannot solve my problems by my own. & 1.82 & 0.629 & Moderate \\
\hline 28 & I have a desire to leave school. & 1.80 & 0.857 & Moderate \\
\hline 7 & Others misunderstand my behaviors & 1.78 & 0.616 & Moderate \\
\hline 14 & I face difficulty in making my decisions. & 1.78 & 0.679 & Moderate \\
\hline 16 & I do not feel the taste of life. & 1.78 & 0.679 & Moderate \\
\hline 4 & I do not exchange with others the greetings. & 1.76 & 0.716 & Moderate \\
\hline 15 & I could not defend my opinions. & 1.74 & 0.664 & Moderate \\
\hline 8 & People do not admit my work when it is done well. & 1.72 & 0.784 & Moderate \\
\hline 10 & I have a feeling of inferiority & 1.72 & 0.640 & Moderate \\
\hline 32 & I feel I did not have my appropriate friend. & 1.72 & 0.784 & Moderate \\
\hline 6 & Others sometimes try to utilize me & 1.70 & 0.707 & Moderate \\
\hline 12 & I am not convinced of my situation. & 1.66 & 0.626 & Low \\
\hline 5 & Do not like attending social occasions. & 1.99 & 0.663 & Low \\
\hline \multicolumn{2}{|c|}{ Total degree } & 2.12 & .3701 & Moderate \\
\hline
\end{tabular}

And to identify the order of the questionnaire's dimensions that expressed the degree of the identity's crisis of the teenagers with hear impairment in Palestine, it is clear from table (4), which showed the means of the questionnaire's dimensions, that the dimension of " feeling trust verses not trust oneself and the others" followed by the Ideological identity and social identity or Interpersonal Ego-Identity, method of entertainment and the relation with other sex and finally the feeling of identity's loss verses mystery of identity. The results agree with the results with the studies of Wafi, 2006 \& Khseifan, 2000.

The researcher attributed this result to the family nurture and the school's systems and laws. People with hearing impairment received a great attention to compensate their feeling of inferiority. But we should not forget that the teenager passes by the level of adolescence where he faces two embarrassed situations: the first one related to his ability which is considered a crisis and the other is the adolescence and the procedures to have his identity developed which can affect his awareness of himself. Others considered the adolescence as the new birth of the person which Hall characterized it: it the stage of the psychological crises, suffering, depression, conflict, 
problems and difficulty in compatibility". According to Erikson, this age's level is critical because the ego identify is formed and this formation is linked with the ability of identifying the teenagers' beliefs and his roles in life by answering the following questions and this what Erikson called the Ego Identify Crisis: Who am I?, What do I want? What are my goals? Where am I going? During the process of this formation and to be able to have specific answer for his questions, the teenagers becomes in a crossroad where he achieves his identity or suffers from diffusion in his identity. Teenagers' failure in identify is represented by the failure to answer the questions and to identify their roles and goals in life (Sultan, 2009).

\subsection{Results Concerning the Second Question}

Are there statistical significant differences at the level of significance $(a \geq 0.05)$ in the identity crisis of the people with hearing impairment attributed to variables; gender, age, economic status and degree and nature of difficulty?

- $\quad$ Results concerning the gender:

The means and the T test's results were calculated and T value for the total degree was (0.993) and the level of significance was (0.326) indicating that there were no differences in the identity crisis of teenagers with hearing impairment attributed to the gender variable. And as other teenagers who are without any disability, the developmental levels which they passed by are similar and the adolescence should be represented by a degree in the crisis. Additionally, the social and family nurture which does not show any discrimination between the gender and treat them well. And the mixed classes play a role in treating the gender equally. This result agrees with the results of the studies of Katabi, 1988 \& Ali, 2007. The results of the study showed no differences between the gender in the identity crisis to the contrary of the study's results of Picciotto (1987) which revealed differences attributed to the gender.

- $\quad$ Results concerning age variable

Table 5. Means and Standard Deviations of the respondents' attributed to age variable

\begin{tabular}{cccc}
\hline Age & N & Mean & Std \\
\hline 13-less than 15 & 30 & 1.6202 & 0.36684 \\
15-less than 18 & 30 & 1.9212 & 0.27172 \\
20-18 & 40 & 2.1409 & 0.24858 \\
\hline
\end{tabular}

It is noted from table (5) that there were differences in the identity crisis of those with hearing impairment attributed to age variable and to find out the significance of these differences, One Way ANOVA was used.

$\mathrm{T}$ value for the total degree was (15.354) and the level of significance was $(0.000)$ which is less than the level of significance $(a \geq 0.05)$ indicating that there were significant differences in the identity crisis of those with hearing impairment attributed to the age variable and the differences were in favor of the age ranged from 18 to 20 years.

And the researcher attributed this result to the idea that the adolescence stage which ranged from 18 to 20 years is considered one of the most difficult stages in Man life span because it is a level of the individual's integration and in his growth as well, and the great amount of imaginations and therefore he will be in a conflict surrounded by depression, incompatibility and anxiety because his physical and mental changes but the beginning of the adolescence stage (13-20) remains an early stage in growth and thinking is still childish. This result agreed with the study's results of Picciotto (1987). The disabled in the adolescence stage faces two embarrassed situations: the first related to his disability as he faces many problems in his school, social and psychological life and the other one is related to the adolescence stage itself where the teenager awareness of the restrictions imposed on him because of his disability and therefore his concept and awareness of himself is affected negatively and as a result he has no trust of his abilities. Although adolescence stage is difficult and critical in general to the teenagers but it is more difficult to teenagers with hearing impairment because the hearing disability itself is considered a crisis (Abdallah, 2004).

\section{- $\quad$ Results concerning the economic status}

Means and standard deviations were calculated to the sample with hearing impairment in the identity crisis attributed to the economic status variable.

It is noted from table (6) lack of apparent differences in the identity crisis of those wit hearing impairment attributed to economic status variable, and to know the significance of these differences, One Way ANOVA was used. 
Table 6. Means and standard deviations of the respondents attributed to the economic status

\begin{tabular}{cccc}
\hline Economic status & $\mathrm{N}$ & Mean & STD \\
\hline Less than 1000 & 28 & 2.0080 & 0.31947 \\
$1000-2000$ & 28 & 1.7802 & 0.43614 \\
More than 2000 & 44 & 1.9604 & 0.32430 \\
\hline
\end{tabular}

The F value of the total degree was (1.601) and a level of significance (0.214) and it is higher than the level of significance $(a \geq 0.05)$ indicating there were no statistical differences in the identity crisis of those with hearing impairment attributed to economic status.

The researcher attributed this result to the economic status which is linked by providing the physical capabilities to meet the physical and the psychological needs and educating him. Because the people with moderate income are the most common and their cultural and environmental situations are close, there were no differences in the economic status.

This study did not agree with any of the previous study; (there were no statistical significant differences in the identity crisis of the people with hearing disability attributed to the economic status variable " but it differed from the Tarshawi's study (2002) which showed differences in the identity crisis attributed to the economic status variable.

-Results concerning the degree of disability

Means and standard deviations were calculated to the sample with hearing impairment in the identity crisis attributed to the degree of disability variable.

Table 7. Means and standard of the respondents attributed to the degree of disability

\begin{tabular}{cllc}
\hline Degree of disability & $\mathrm{N}$ & Mean & Std \\
\hline Simple & 16 & 1.9432 & 0.31091 \\
Moderate & 60 & 2.0010 & 0.37794 \\
Very & 24 & 1.6970 & 0.26949 \\
\hline
\end{tabular}

It is noted from table (7) that there were differences in the identity crisis of those with hearing impairment attributed to age variable and to find out the significance of these differences, One Way ANOVA was used

$\mathrm{T}$ value for the total degree was (3.340) and the level of significance was (0.000) which is less than the level of significance $(a \geq 0.05)$ indicating that there were significant differences in the identity crisis of those with hearing impairment attributed to the degree of disability and the differences were in favor of the moderate disability.

And the researcher analyzed this result that whenever the degree of disability is simple, the degree of identity crisis will be less, on the contrary to the one who has moderate disability and as a result his degree of identity crisis will be higher. The simple identity enable the individual to interact with society, and hear people's voices with different degrees plus he can rely on himself more than the one with moderate or strong disability and therefore, the development of identity crisis increased which is on the contrary to the one who has strong disability and he cannot hear or communicate with the society and thus the concept of identity is reduced and there is a possibility to have an identity crisis.

Moderate hearing disability could be a reason in the problem of identity and could affect their independence plus their appreciation to themselves. So to have his identity developed, the person with hearing impairment should have a philosophy based on understanding the self and when he succeeded in doing so, he is considered socially and psychologically mature and ready to move from adolescence stage to the adulthood. Some of the most important indicators of this success are: independency, acquiring values, accepting his sex, identifying and working on his purposes and objectives to feel secure with himself and with others (Fahmi, 1978).

This result does not agree with any one of the previous studies, but it varied with the study of Khatab(2007) which showed lack of differences attributed to the degree of the visually disabled people.

Results concerning nature of the disability

$\mathrm{T}$ test and means of the respondents' answers were calculated. 
T value for the total degree was (0.977) and the level of significance was $(0.339)$ which is less than the level of significance $(a \geq 0.05)$ indicating that there were no significant differences in the identity crisis of those with hearing impairment attributed to the nature of the disability.

The researcher attributed this result to the family nurture and the special care and attention which they will receive regardless the nature of their disability; genetic or environmental. And they were not affected by the nature of their disability because they did not feel any shortage in their physical or psychological needs. The nature of difficulty is naming the existence of disability and it has no relation with the identity development of the teenagers with hearing impairment because they were in one environment and they have the same values whether the difficulty nature's was genetic or environmental.

There was no previous studies that agrees or disagree with the current study; there were no differences in the identity crisis of the people with hearing impairment attributed to the nature of difficulty.

\section{Recommendations}

1. Necessity of paying attention to this category and helping it to pass crisis of adolescence through researches and holding counciling programs (psychological support, meetings, training courses) to the people with hearing disability, their parents and their teachers to help in developing the appropriate concept of identity and suggesting cultural programs so as to increase their awareness ad accept their selves.

2. Paying attention to the teenagers with hearing impairment psychologically to help them adopt to the constraints imposed on them and to develop their correct concept of identity.

3. Conducting comparative studies with other disabilities in the field of identity crisis and with the Non-disabled.

\section{References}

Abdgader, M. (1984). Developmental psychology and its theories. Cairo: Azhar University.

Abdmo 'ti, H. (1991). Family nurture and its impact in forming the identity of the university youth. College of Education, Zaqaziq University.

Abdrahim, A. (1997). Developing disabled children. Dar Gharib for press, publishing and distribution, Cairo.

Abdrahim, F., \& Bshai, H. (1988). Psychology of the exceptional children and strategies of special education (2nd ed.). Library of Dar qalam, Kuwait.

Abdrahman, M. (1998). Personal traits and its relation with methods of facing identity crisis of the secondary and university students, studies in the psychological health. Cairo: Dar Gibt for press and publishing.

Abo hatab, F., \& Sadeq, A. (1990). Human growth (2nd ed.). Library of the al-anglo Egyptain, Cairo.

Adel, A. (2004). Disabilities. Cairo: Dar Rashad.

AL Tarshawy, K. (2002). Identity crisis of the juvenile delinquents in comparison to the non- delinquents in Gaza governorates in light of some Variables (Unpublished Thesis). College of Education, psychology Department, Islamic University, Ghaza.

Al-Ashqar, A. (2002). Services presented to the deaf children and their relation with the personal traits in Ghaza Governorate (Unpublished Thesis). College of Education, Islamic University, Ghaza.

Al-dosoqi, M. (2003). Psychology of growth from birth to adolsence. Library of al-anglo Egyptain, Cairo.

Al-Kas, R. (2008). The statement care of the disabled in the Islamic educational thought in the light of the problems they face (Unpublished Thesis). College of Education, Department of Education Foundation, Islamic University, Ghaza.

Al-Khateeb, J. (2005). Introduction in hearing disability (2nd ed.). Dar Fikr, Amman, Jordan.

Al-Maghazi, I. (2004). Our disabled Children ....to where? Ward Library, Mansoora, Egypt.

Al-Migati, N. (2001). Letures in Deafr Education. A course in training the teachers of the Deaf. PROJECT OF preparatory of the Deaf, Corporation \& International vision institutions, Ghaza, Palestine.

Al-Minizl, A. (1994). Identity Crisis: Comparative study among the Juvenile delinquents and non-Juvenile delinquents. Derasat: Human sciences, 21(1).

Al-Qureiti, A. M. (2005). The psychology of the people with special needs and their education (4th ed.). Dar Fikr Arabi, Cairo, Egpyt.

Al-Rosan, F. (2001). Psychology of exceptional children: Introduction in the special Education (5th ed.). Dar 
Fikr, Amman, Jordan.

Al-Wahidi, L. (2012). Moral Judgment and its relation with ego identity of a sample of deaf and blind teenagers in Ghaza Govornorates (Unpublished thesis). Ghaza: University of Azhar.

Al-Zreiqat, I. (2003). Hearing Disability. Dar Wael for Publishing, Amman, Jordan.

Barakat, A. (1981). Disabled Education in Arab World. Dar Mareikh, Riyadh.

Bauman - waengler.j. (2012). Phonological Impairments: A clinical Focus. Boston: Allyn. Bacon.

Bellis, T. (2013). When the brain can't hear: Unraveling the mystery of auditory processing disorder. New York: Atrin Book.

Erikson, E. H. (1968). Identity formation: Youth and Crisis. New York: Norton.

Erikson, E. H. (1994). Identity: Youth and Crisis. New York.

Ghamdi, H. A. (2001). Relation of ego identity formation with moral reasoning thinking of a samole of male students in the stage of adolescence in Saudi Arabia. Egyptian journal of psychological studies, (29).

Homud, F. (2009). Levels of identity formation and its relation with its basic fields of a sample of the first secondary grade's students form both gender, Unpublished Thesis. Journal of Damascus University, 27.

Hussein, M. (1986). Psychology of exceptional children and their education. Dar Fikr Jameei, Alexandria.

Ibn kather, I. A. F. (n. d.). Ibn Kather Enterpretation (Vol. 4). Ryadh modern library, Ryadh, Saudi Arabi.

Ismael, M. (1989). The child from bregnancy to Adulthood (Part 2). Kuwait-Dar Fikr.

Ismael, M. (2001). The child from bregnancy to Adulthood: The child and the teenager (5th ed.). Dar Al-Qalam for publishing \& Distribution, Kuwait.

Kafarkuis, W. (1976). Juvenile delinquency, translation by Enayat. Egyptian general assembly of books.

Kroger, M., \& Marica, J. E. (2010). Identity status change during adolescence and young adulthood. Ameta analysis, j press psychology.

Misn, P. (1986). Basics of childhood and adolescence psychology (Trans. by A. Salama). Falah Library, Kuwait.

Mohamd, A. (2004). Talented children with disabilities. Cairo: Dar Rashad.

Morsi, A. B. (1988). Comparative study of the anxiety level and its relation with identifying the identity of the teenagers who are smokers and non smokers (Unpublished thesis). College of Art, University of Ein Shams.

Mostafa, F. (1978). Psychological adaptation. Cairo: Dar masr for Press.

Mussen, P. (1984). Child Development and Personality. USA: Harper\& Row Publishers.

Salamh, M. (1991). Psychological counseling: Developmental perspective. Anglo Egyptian library -Egypt.

Shata, A. (1992). Parents' attitudes towards their deaf children and its relation with these children's concept of identity (Unpublished thesis). Institute of higher education of childhood, EIN Shams University.

Suliman, J. (1988). Cross - sectional Study of Psychosocial growth of the students of preparatory and secondary levels according to Erikson theory (Unpublished thesis). Azhar University, Cairo.

Sultan, I. (2009). Teenagers' Physical Development. Jorrdan: Dar Saffa for publishing and distribution.

The Palestinian Central Bureau of Statistics. (2011). World of Books, Cairo, Egypt.

Wafi, L. (2006). Behavioral diffusions and their relation with the level of psychology compatibility of the deaf and blind children (Unpublished thesis). College of Education, department of psychology, Islamic University, Ghaza.

Ynis, A., \& Masri, H. (1991). Taking care of the disabled child psychology, healthy and socially. Dar fikr Al-Arabi, Cairo.

\section{Copyrights}

Copyright for this article is retained by the author(s), with first publication rights granted to the journal.

This is an open-access article distributed under the terms and conditions of the Creative Commons Attribution license (http://creativecommons.org/licenses/by/3.0/). 